\title{
Modelling and Prediction Using Regression, ANN and Fuzzy Logic of Real Time Vibration Monitoring on Lathe Machine in Context of Machining Parameters
}

\author{
Saurin Sheth, Bhavin S. Modi, Dipal Patel and Ashish \\ B. Chaudhari
}

\begin{abstract}
Machine tool vibration plays a dominant role in the surface finish, dimensional and geometrical tolerances of the machined work piece. Condition of the machines includes collected data, such as vibration analysis, oil and wears debris analysis, ultrasound, temperature and performance evaluation. Out of these the vibrations have been measured and its effect has been studied. The present paper deals with the measurement of acceleration during machining of Cast Iron on lathe machine. $3^{3}$ full factorial design of experiments were selected, experiments are performed by varying machining parameters such as spindle speed, feed rate and depth of cut. ANOVA and Regression analysis has been carried out to know the significance of these parameters. Even Artificial Neural Network (ANN) and Fuzzy Logic based models have been developed to predict Acceleration in the context of these input parameters. The predicted results obtained from the developed models are compared with the experimental one. Results shows that the developed models having more than 95\% accuracy, which leads the use of it in predicting the acceleration within the range of the specified input parameters for a given machine too.
\end{abstract}

Keywords--- Machining, Acceleration, ANOVA, Regression Model, ANN, Fuzzy Logic, Condition Monitoring

\section{INTRODUCTION}

$\mathrm{N}$ EW generation of machine tools are capable of manufacturing the goods with higher accuracy, due to their inherent capabilities. But the old machine tools may not be able to fulfill the same functional requirements, due to many aspects. The major aspect is machine tool vibrations during condition monitoring. Turning, the most versatile machining process, covers around $70 \%$ share of the machining on lathe machine. DOE is an experimental strategy in which effects of multiple factors are studied simultaneously by

Saurin Sheth, Mechatronics Engineering Department, G H Patel College of Engineering \& Technology, Vallabh Vidyanagar-388120, India.

Bhavin S. Modi, Mechanical Engineering Department, BVM Engineering College, Vallabh Vidyanagar-388120, India. E-mail:bhavinmodi503@gmail. com

Dipal Patel, Mechanical Engineering Department, Chandubhai. S. Patel Institute of Technology, Changa- 388421, Gujarat, India.

Ashish B. Chaudhari, Mechanical Engineering Department, Chandubhai. S. Patel Institute of Technology, Changa-388421, Gujarat, India.

DOI: 10.9756/BIJMMI.8078 running tests at various levels of the factors. The tool Design of Experiments (DOE) can be used to know the significance of machining parameters on the machine tool vibration and even it helps in deciding the most significant one.

\section{LITERATURE REVIEW}

D. Zhou et al., [1] introduced a systematic methodology for the design of an integrated condition monitoring and fault diagnosis expert system for modern manufacturing systems. This is an integrated and intelligent system with a modular and re-configurable structure, and it has the functions of condition monitoring, fault diagnosis and maintenance planning. The system has been implemented for FFS-1500-2 FMS and it can also be applied to other manufacturing systems. Aiwina Heng et al., [2] reviewed various state of art challenges and opportunities during rotary machine diagnostic system. Lin Ma [3] discusses new directions for the condition monitoring for sustainability. Vinay. V. N [4] was studying the effect of unbalanced mass of motor spindle assembly for lathe machine. S. Saravanan et al., [5] study about the causes of failure of critical components and subsystems of lathes using failure data. Faulty bearing in lathe can be identified by using online vibration monitoring and surface roughness monitoring. For defective bearing conditions, significant peaks at the bearing fault frequencies are observed. Pratik Patel et al., [6,7] analyzed the effect of machining parameters on MRR and Spread for flashing operation of ball bearing ball. They have performed ANOVA and regression analysis for the same. Pratihar [8] review that soft computing based expert systems like ANN, Fuzzy and ANFIS can be used to establish input output relationships of various manufacturing processes. The paper reveals that a reasonably good results were obtained using soft computing techniques.Aiwina Heng et al., [19] have suggested a use of artificial neural network for prediction of failure of machinery. The ability to forecast machinery failure helps in reducing maintenance costs, operation downtime and safety hazards. This implies the need of proper selection of speed, feed and depth of cut to reduce the level of vibration, which enhances the machine tool life. 


\section{EXPERIMENTATION}

\section{A. Material Selection}

ASTM A48 Class 40 - Pearlite Gray Cast Iron is used to perform for the experimentation. It represents the same graphite distribution, however, in an essentially pearlite matrix, which yields better mechanical properties and better heat treatment response. Hardness is 198-285 BHN. It is widely used to manufacture pistons, valves, dies etc. The size of the work piece is $30 \mathrm{~mm}$ diameter and $150 \mathrm{~mm}$ length.

Table 1 shows the chemical composition of the work piece material.

Table 1: Chemical Composition

\begin{tabular}{|l|l|l|l|l|l|}
\hline Material & C & SI & Mn & S & P \\
\hline $\begin{array}{l}\text { Percentage } \\
\text { contribution } \\
(\%)\end{array}$ & $3.80-$ & $2.30-$ & $0.40-$ & 0.20 & 0.10 \\
& & 2.70 & 0.80 & max. & max. \\
\hline
\end{tabular}

\section{B. Cutting Tool}

High speed steel (HSS) is a high carbon ferrous alloy consisting of $\mathrm{W}, \mathrm{Mo}, \mathrm{Cr}, \mathrm{V}$, and Co. HSS is inexpensive compared to other tool materials. It has excellent fracture toughness and fatigue resistance. HSS is suitable for use only at limited cutting velocities of $30-70 \mathrm{~m} / \mathrm{min}$ because of its limited wear resistance and chemical stability. Table 2 shows the composition of HSS tool[9].

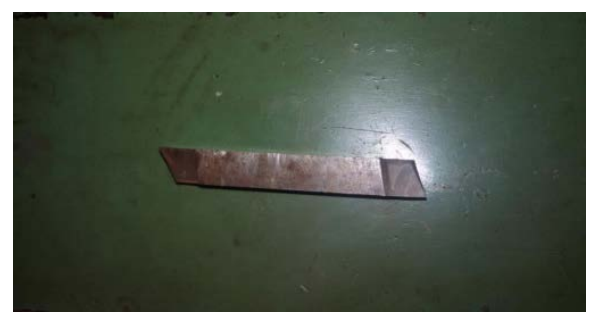

Fig. 1: Signal Point HSS Tool

Table 2: Composition of HSS Tool Bit

\begin{tabular}{|l|l|l|l|l|l|}
\hline Contents & C & W & Cr & V & Co \\
\hline Percentage\% & 0.80 & 20 & 4 & 2 & 5 and 10 \\
\hline
\end{tabular}

\section{Experimental Setup}

The Experiment setup developed at the workshop of CSPIT, CHANGA is shown in Fig. 2 [9]. For vibration monitoring the sensor was mounted to the tool post of the machine. The used DAQ system includes Physical input/output signals as shown in figure (3), DAQ hardware as shown in figure (4) and Driver software. DAQ hardware act as interface between computer and outside world. Machining parameters spindle speed, feed rate and depth of cut varied at 3 levels as shown in table $3.3^{3}$ Full factorial design is selected to perform the reliable experiments. As per this total 27 experiments were performed and acceleration is measured [10].

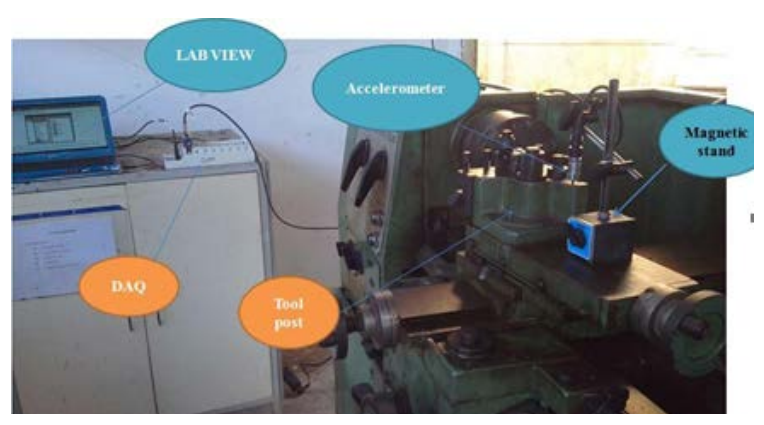

Fig. 2: Experimental Setup

Table 3: Factors with Levels

\begin{tabular}{|l|l|l|l|}
\hline Factor & Level 1 & Level 2 & Level 3 \\
\hline Spindle speed(RPM) & 125 & 250 & 350 \\
\hline Feed rate (mm/rev) & 0.05 & 0.1 & 0.15 \\
\hline Depth of cut (mm) & 1 & 2 & 3 \\
\hline
\end{tabular}

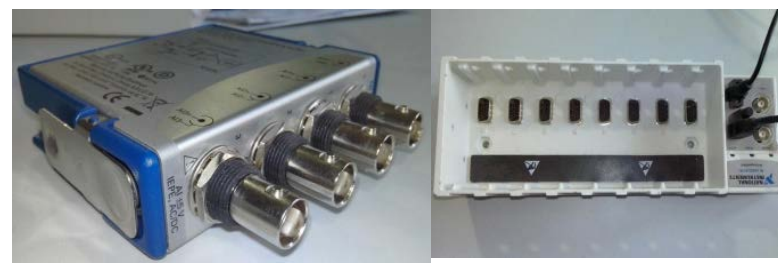

Fig. 3: NI 9234 Physical Input/Output Signals

Fig. 4: DAQ

Hardware Device

\section{Measurement of Acceleration}

The accurate measurement technique is required to develop reliable models. Acceleration measurement was done using NI 9234 module. Figure (5) shows the interfacing of DAQ system with sensor and Lab View. During turning operation, acceleration signal collected by piezo sensor goes to lab view software by using a DAQ device [11]. Figure (6) shows the sample signal collected by lab view, from which the interest is to find the max acceleration value. The outcomes of 27 experiments are shown in table 4.

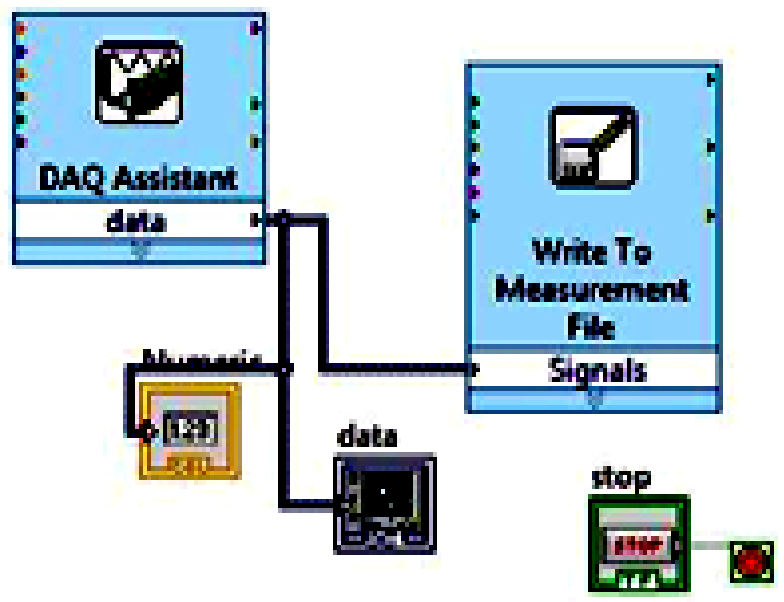

Fig. 5: Labview Diagram 


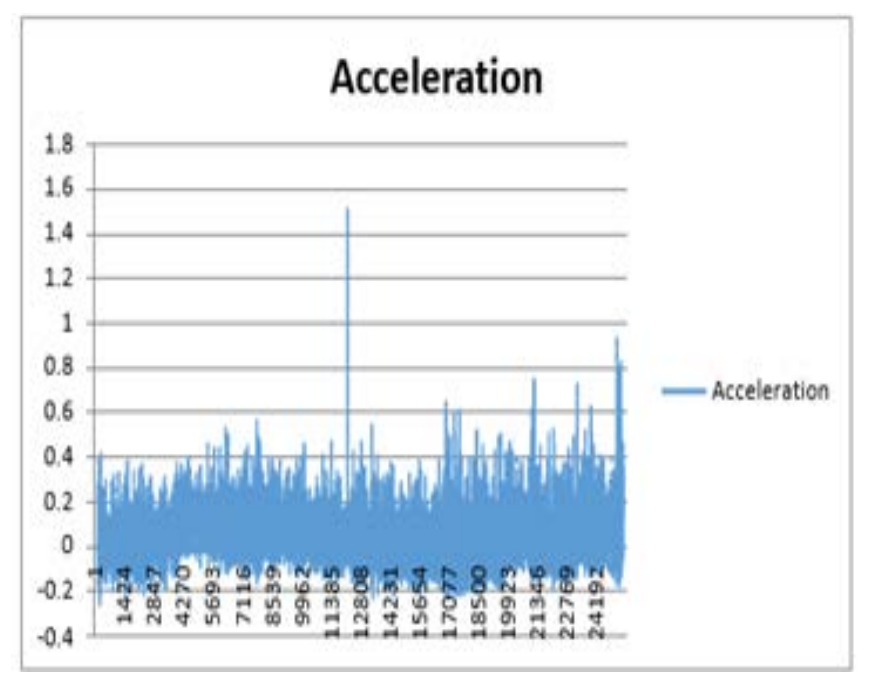

Fig. 6: Typical Acceleration Signal

Table 4: Experimental Results

\begin{tabular}{|c|c|c|c|c|}
\hline 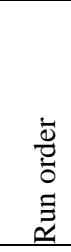 & 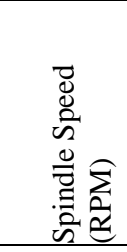 & 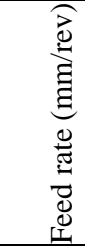 & 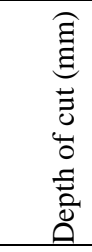 & 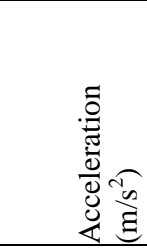 \\
\hline 1 & 125 & 0.05 & 1 & 1.009661 \\
\hline 2 & 125 & 0.05 & 2 & 1.156552 \\
\hline 3 & 125 & 0.05 & 3 & 1.592348 \\
\hline 4 & 125 & 0.1 & 1 & 1.013119 \\
\hline 5 & 125 & 0.1 & 2 & 1.329162 \\
\hline 6 & 125 & 0.1 & 3 & 1.895578 \\
\hline 7 & 125 & 0.15 & 1 & 1.304193 \\
\hline 8 & 125 & 0.15 & 2 & 1.956258 \\
\hline 9 & 125 & 0.15 & 3 & 2.398151 \\
\hline 10 & 250 & 0.05 & 1 & 1.079311 \\
\hline 11 & 250 & 0.05 & 2 & 1.297001 \\
\hline 12 & 250 & 0.05 & 3 & 1.88997 \\
\hline 13 & 250 & 0.1 & 1 & 1.308859 \\
\hline 14 & 250 & 0.1 & 2 & 1.801105 \\
\hline 15 & 250 & 0.1 & 3 & 1.996056 \\
\hline 16 & 250 & 0.15 & 1 & 1.737262 \\
\hline 17 & 250 & 0.15 & 2 & 2.013218 \\
\hline 18 & 250 & 0.15 & 3 & 2.701215 \\
\hline 19 & 350 & 0.05 & 1 & 1.124168 \\
\hline 20 & 350 & 0.05 & 2 & 1.716078 \\
\hline 21 & 350 & 0.05 & 3 & 2.112353 \\
\hline 22 & 350 & 0.1 & 1 & 1.877681 \\
\hline 23 & 350 & 0.1 & 2 & 2.126821 \\
\hline 24 & 350 & 0.1 & 3 & 2.365218 \\
\hline 25 & 350 & 0.15 & 1 & 1.993757 \\
\hline 26 & 350 & 0.15 & 2 & 2.627641 \\
\hline 27 & 350 & 0.15 & 3 & 3.115454 \\
\hline
\end{tabular}

\section{ANALYSIS OF THE RESUlTS}

\section{A. Analysis of Variance (ANOVA)}

Table 5: ANOVA Table

\begin{tabular}{|l|l|l|l|l|l|}
\hline Source & DF & SS & MS & F & P \\
\hline Spindle Speed 2 & 1.6435 & 0.8218 & 41.29 & 0.000 \\
\hline Feed rate & 2 & 2.6580 & 1.3290 & 66.77 & 0.000 \\
\hline D.O.C & 2 & 3.2284 & 1.6182 & 81.10 & 0.000 \\
\hline Error & 20 & 0.3981 & 0.0199 & & \\
\hline Total & 26 & 7.9280 & & & \\
\hline S = 0.141082 & \multicolumn{2}{|l|}{ R-Sq $=94.98 \%$} & R-Sq(adj) = 93.47\% \\
\hline
\end{tabular}

The ANOVA Table 4 shows that the speed, Feed rate and Depth of cut are significant parameters. The percentage contribution of spindle speed, feed rate and depth of cut are $20.73 \%, 33.52 \%$ and $40.72 \%$ respectively. Figure 7 and 8 shows the Main effect Plot and interaction plots for Spindle Speed, Feed and Depth of Cut. Itseems that acceleration increases with increases of spindle speed, feed and Depth of Cut. Figure 8 Shows that interaction plot for Spindle Speed, Feed, and depth of cut. It seems that there is no interaction effect present between the input variables.

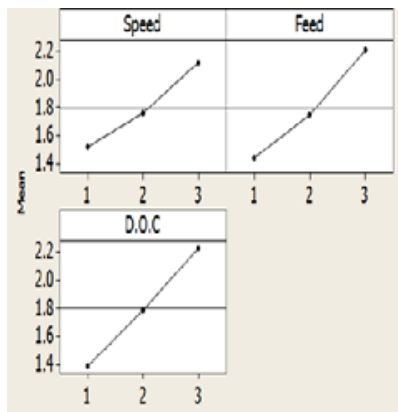

Fig. 7: Main Effect Plot

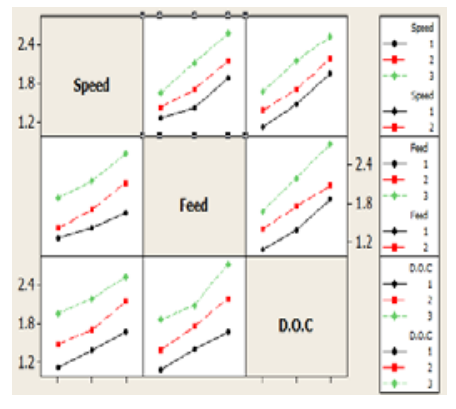

Fig. 8: Interaction Plot

\section{B. Regression Model}

Regression analysis is a statistical tool for the investigation of relationships between variables. Here second order regression model is developed using Minitab 16 software which is show in equation 1 . The R-Sq value is the variability in the data accounted by the model in percentage. The R-Sq value for acceleration model is close to 1 , which shows the high correlation that exists between the experimental and predicted values [10, 18].

Acceleration $=1.0814-0.279337 *$ spindle speed $-0.398142 *$ feed $-0.00874461 *$ depth of cut $+0.0592333 *$ spindle speed 2 $+0.168124^{*}$ spindle speed* feed $+0.0776329 *$ feed $2+$ 0.160946* feed* depth of cut $+0.097632 *$ depth of cut * spindle speed $+0.0259268 *$ depth of cut2 - 0.0472199* spindle speed $*$ feed $*$ depth of cut $(\mathrm{R}-\mathrm{Sq}=96.70 \%)$ 


\section{Artificial Neural Network}

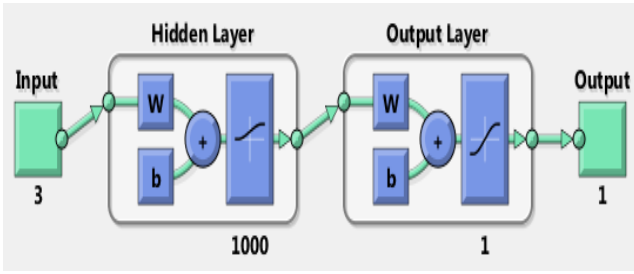

Fig. 9: ANN Model in MATLAB 2012a

ANN is the soft computing technique in which experimental data are used to train the neurons at its learing stage. Fig 9 indicates the architecture used between input and output parameter. Here spindle speed, feed rate, depth of cut is three input variable and acceleration is the response. Total 1000 iterations are performed for modelling using ANN technique. Here back propagation algorithm is used to develop a model using MATLAB tool box $[12,13]$. The predicted values obtained from the model are shown in table 6 .

\section{Development of Fuzzy Logic based Model to Predict Acceleration}

Fuzzy logic (FL) is a common element of Expert System with an increasing rate of interest and widely used over the past few years due to its successful applications in many control and prediction systems. It suits very well in defining the relationship between inputs and desired outputs of a system, where its extra ordinary controlling and reasoning capability made its way to the application of many complex industrial systems. Fuzzy system consist few inputs, output(s), set of predefined rules and a defuzzification method with respect to the selected fuzzy inference system. $[14,15,16]$.

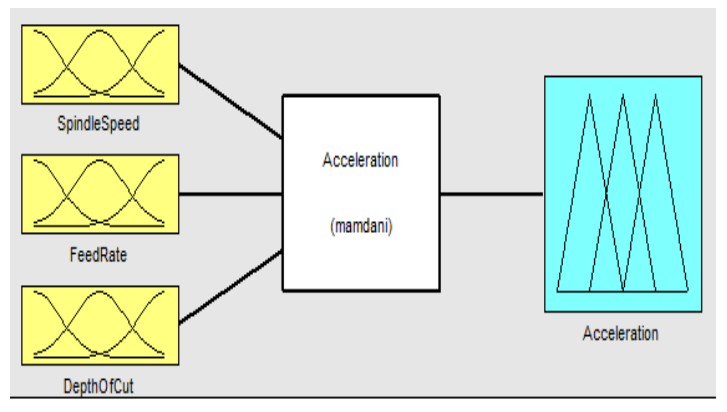

Fig. 10: Fuzzy Logic System

MATLAB 12 Fuzzy Logic Tool Box is used to developed Fuzzy model. Figure 10indicates the structure of fuzzy system having three input variables viz. spindle speed, feed rate and depth of cut and response is acceleration. Fuzzy modeling basically involves three main processes viz. fuzzification, fuzzy inference and defuzzification.

\section{i. $\quad$ Membership Functions for Inputs and Output Fuzzy Variables}

In choosing the membership functions for fuzzyfication, the event and type of membership functions are mainly dependent upon the relevant event. Triangular shape of membership function is employed to describe the fuzzy sets for input and output variables. Triangular membership function is generally used and possesses gradually increasing and decreasing characteristics with only one definite value.
Figure 11 shows membership functions for each input variable and figure 12 shows membership functions for response [15, 16]
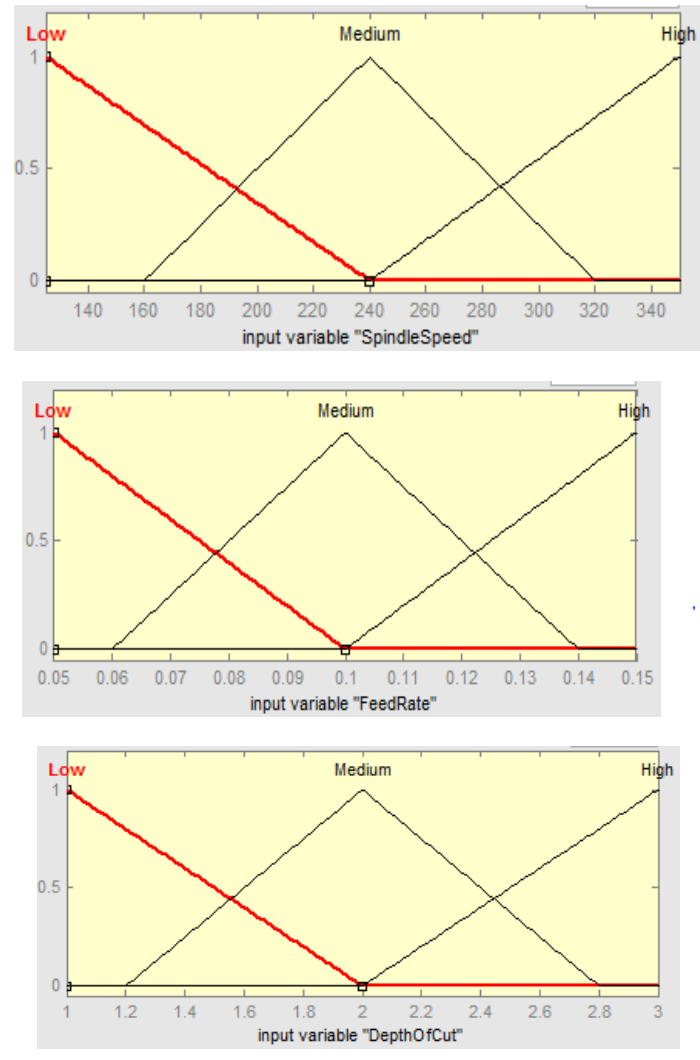

Fig. 11: Membership Functions for Spindle Speed, Feed, Depth of Cut

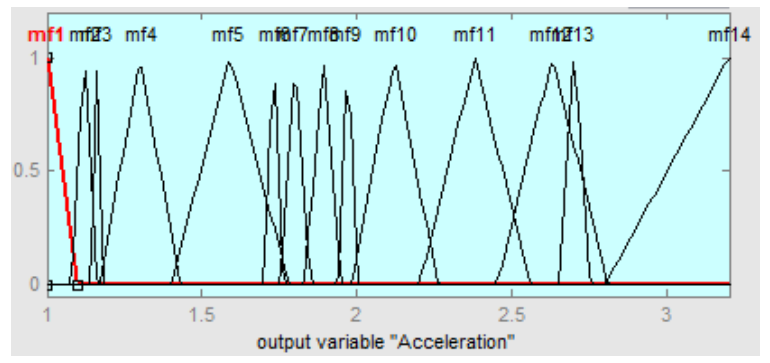

Fig. 12: Membership Function for Acceleration

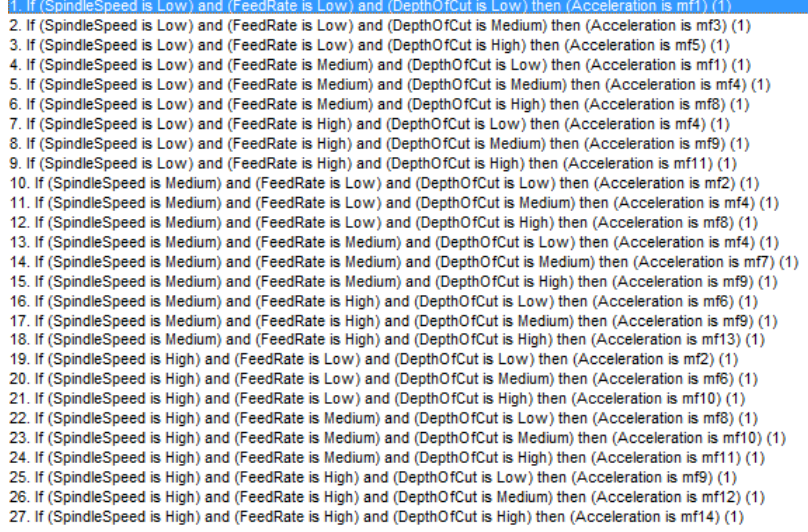

Fig. 13: Fuzzy Rules 


\section{ii. $\quad$ Fuzzy Rules}

Based on three input variable and their three membership values a set of 27 rules have been constructed based on the actual experimental Acceleration. Figure 13 shows the set of rules.

\section{iii. Defuzzyfication}

Defuzzyfication is the conversion of the fuzzy quantity to real value. The selection of the method is important as it greatly influences the speed and accuracy of the model. In this model, centroid of area (COA) defuzzyfication method is used due to its wide acceptance and capability in giving more accurate result compared to other methods [15]. Figure 14 shows fuzzy surfaces between the Spindle Speed, Feed Rate, Depth of Cut and Acceleration.

\section{iv. Prediction of Acceleration using developed Fuzzy Logic Model}

Figure 15 shows an example of prediction of Acceleration using developed Fuzzy logic model.
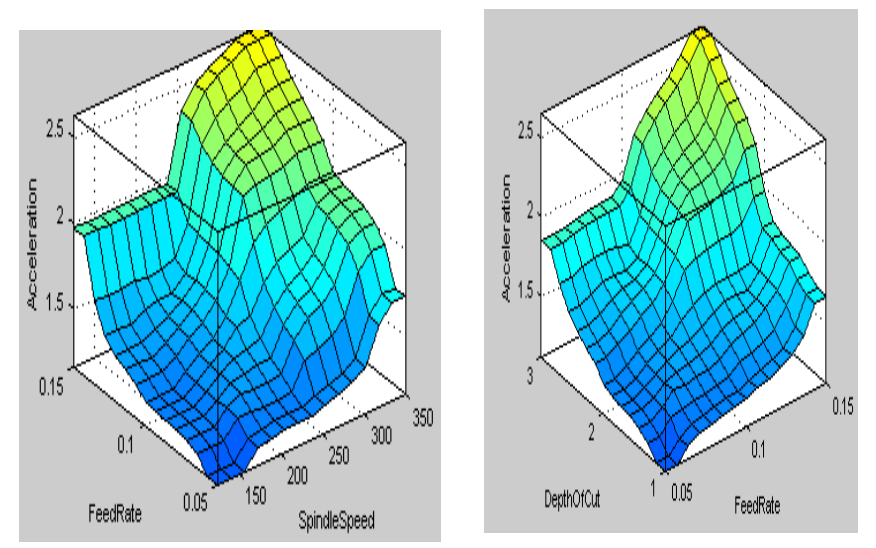

The values of Spindle speed, Feed and Depth of cut are taken 125RPM, $0.05 \mathrm{~mm} / \mathrm{rev}$ and $1 \mathrm{~mm}$ respectively and the predicted value of Acceleration obtained by model is 1.03 $\mathrm{m} / \mathrm{s}^{2}$ which is shown in Figure 15.Rest of the prediction for each treatment combinations are shown in table 6 .

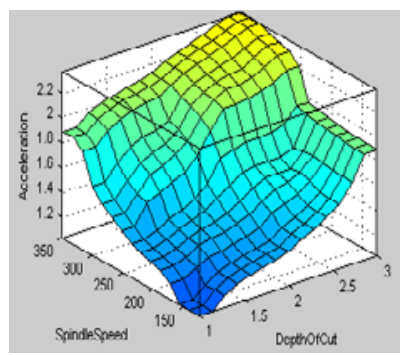

Fig. 14: Fuzzy Surface Plots between Spindle Speed, Feed Rate, Depth of Cut and Acceleration

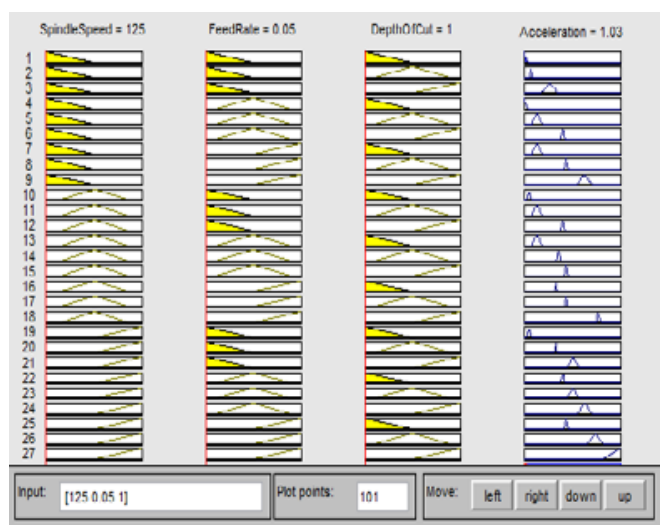

Fig. 15: Predicted Value of Acceleration Using Fuzzy Model

Table 6: Acceleration Values

\begin{tabular}{|c|c|c|c|c|c|c|c|}
\hline $\begin{array}{l}\text { Run } \\
\text { order }\end{array}$ & Spindle Speed & Feed rate & Depth of cut & Experimental results & $\begin{array}{c}\text { ANN } \\
\text { predicted }\end{array}$ & $\begin{array}{l}\text { Regression } \\
\text { predicted }\end{array}$ & $\begin{array}{r}\text { Fuzzy } \\
\text { predicted }\end{array}$ \\
\hline 1 & 125 & 0.05 & 1 & 1.009661 & 1.0522 & 0.93745219 & 1.03 \\
\hline 2 & 125 & 0.05 & 2 & 1.156552 & 1.1524 & 1.21784678 & 1.16 \\
\hline 3 & 125 & 0.05 & 3 & 1.592348 & 1.5676 & 1.55009497 & 1.59 \\
\hline 4 & 125 & 0.1 & 1 & 1.013119 & 1.0333 & 1.05405899 & 1.03 \\
\hline 5 & 125 & 0.1 & 2 & 1.329162 & 1.3834 & 1.44817968 & 1.3 \\
\hline 6 & 125 & 0.1 & 3 & 1.895578 & 1.9376 & 1.89415397 & 1.89 \\
\hline 7 & 125 & 0.15 & 1 & 1.304193 & 1.2949 & 1.32593159 & 1.3 \\
\hline 8 & 125 & 0.15 & 2 & 1.956258 & 1.9949 & 1.83377838 & 1.97 \\
\hline 9 & 125 & 0.15 & 3 & 2.398151 & 2.365 & 2.39347877 & 2.38 \\
\hline 10 & 250 & 0.05 & 1 & 1.079311 & 1.0678 & 1.05435189 & 1.12 \\
\hline 11 & 250 & 0.05 & 2 & 1.297001 & 1.1806 & 1.38515928 & 1.32 \\
\hline 12 & 250 & 0.05 & 3 & 1.88997 & 1.8651 & 1.76782027 & 1.96 \\
\hline 13 & 250 & 0.1 & 1 & 1.308859 & 1.3191 & 1.29186279 & 1.35 \\
\hline 14 & 250 & 0.1 & 2 & 1.801105 & 1.7487 & 1.68917638 & 1.91 \\
\hline 15 & 250 & 0.1 & 3 & 1.996056 & 1.8828 & 2.13834357 & 2.18 \\
\hline 16 & 250 & 0.15 & 1 & 1.737262 & 1.7279 & 1.68463949 & 1.77 \\
\hline 17 & 250 & 0.15 & 2 & 2.013218 & 1.9501 & 2.14845928 & 2.3 \\
\hline 18 & 250 & 0.15 & 3 & 2.701215 & 2.774 & 2.66413267 & 2.83 \\
\hline 19 & 350 & 0.05 & 1 & 1.124168 & 1.1551 & 1.28971819 & 1.12 \\
\hline 20 & 350 & 0.05 & 2 & 1.716078 & 1.6675 & 1.67093838 & 1.73 \\
\hline 21 & 350 & 0.05 & 3 & 2.112353 & 1.8051 & 2.10401217 & 2.12 \\
\hline 22 & 350 & 0.1 & 1 & 1.877681 & 1.8501 & 1.64813319 & 1.89 \\
\hline 23 & 350 & 0.1 & 2 & 2.126821 & 2.0305 & 2.04863968 & 2.12 \\
\hline 24 & 350 & 0.1 & 3 & 2.365218 & 2.6203 & 2.50099977 & 2.38 \\
\hline 25 & 350 & 0.15 & 1 & 1.993757 & 1.9738 & 2.16181399 & 1.97 \\
\hline 26 & 350 & 0.15 & 2 & 2.627641 & 3.0832 & 2.58160678 & 2.63 \\
\hline 27 & 350 & 0.15 & 3 & 3.115454 & 3.0832 & 3.05325317 & 3.07 \\
\hline
\end{tabular}




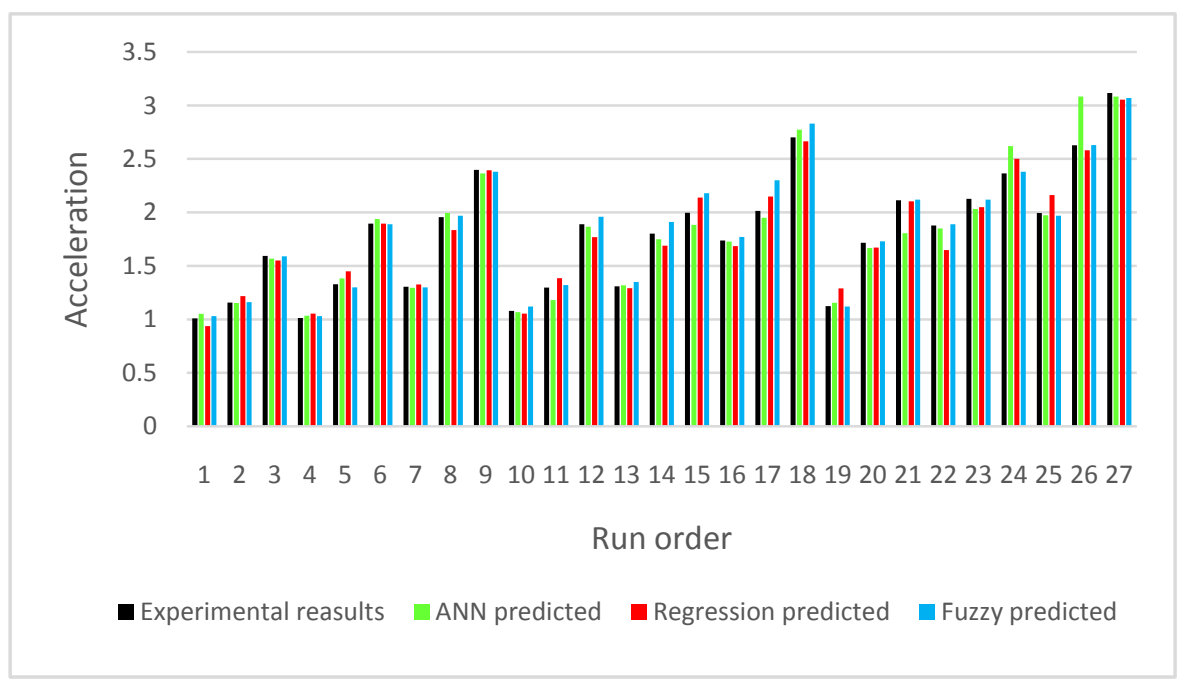

Fig. 16: Comparison of Acceleration Results with Different Model

\section{CONCLUSION}

- ANOVA shows that spindle speed, feed rate, and depth of cut are the most significant parameters. Their contributions are $20.73 \%, 33.52 \%$ and $40.72 \%$ respectively.

- For achieving minimum acceleration we have to keep spindle speed, feed, and depth of cut at low level.

- It is found that the average error related to Regression model, ANN model and fuzzy logic model are $3.7726 \%, 4.7852 \%$ and $2.32 \%$ respectively.

- The predicted and measured values are fairly close as shown in figure 16, which indicates that the developed models can be effectively used to predict the Acceleration in vibration monitoring with more than $95 \%$ confidence intervals.

- The work can be extended by measuring the surface roughness and geometrical tolerances viz. cylindricity, circularity, run out to know the impact of vibrations on it. Later on multi objective optimization can be carried out [17].

\section{REFERENCES}

[1] D.Zhou,Y.Chen,Y.Fuhz and Y.Nee, "Integrated Condition Monitoring and Fault Diagnosis for Modern ManufacturingSystems”,CIRP Annals Manufacturing Technology, Volume 49, Issue 1, 2000, Pp 387-390, 2000.

[2] Aiwina Heng, Sheng Zhang, AndyC.C.Tan, and JosephMathew, "Rotating Machinery Prognostics: State Of The Art, Challenges And Opportunities”, Mechanical Systems and Signal Processing, Volume 23, Pp 724-739, 2009.

[3] Lin Ma, "Condition Monitoring in Engineering Asset Management", 12th Asia-Pacific Vibration Conference, Hokkaido University, Japan, Pp 1-16, 2004.

[4] V.N.Vinay, "Study of In-Situ Dynamic Balancing of SpindleChuck Assembly of CNC Lathe”, International Journal of Mechanical and Industrial Engineering, ISSN No. 2231 -6477, Volume-1, Issue-4, 2012.

[5] S.Saravanan and G.S.Yadav, "Condition Monitoring Studies on Spindle Bearing of a Lathe", The International Journal of Advanced Manufacturing Technology, July 2006, Volume 28, Issue 9-10, Pp 993$1005,2013$.

[6] Pratik J.Patel and SaurinSheth, " Effect of Various Parameters on Material Removal Rate in Flashing Operation of Precision Steel Ball
Manufacturing Process”, Proceedings of the 1st International and 16th National Conference on Machines and Mechanisms (iNaCoMM2013), Pp. 332-338,2013

[7] Pratik J. Patel, SaurinSheth and PurviChauhan, “ Effect of Various Parameters on Spread in Flashing Operation of Precision Steel Ball Manufacturing Process" Procedia Materials Science, Volume 5, Pp. 2224-2232, 2014

[8] Dilip Kumar Pratihar, “ Expert Systems in Manufacturing Processes using softComputing ", International Journal of Advanced Manufacturing Technology,DOI: 10.1007/s00170-015-7285-X, Vol 78, 2015.

[9] Ashish.B.Chaudhari, Dipal Patel and Bhavin S. Modi, "Experimental and Prediction Analysis of Real Time Vibration Monitoring of Different Machining Parameter on Lathe Machine” Proceedings of International Conference on Advances in Materials, Manufacturing and Applications (AMMA 2015), Pp. 155-161, 2015.

[10] Douglas C. Montgomery, "Design and Analysis of Experiments", 7th Edition, John Wiley \& Sons, 2009.

[11] LodovicoMenozzi, "MachineCondition Monitoring with National Instruments Technologies”, Business Development center-Europe.

[12] Tejas Patel, SaurinSheth, Bhavin S. Modi and Pathik Patel, "Experimental Investigation And Forecast of Weld Penetration in MIG Welding Process onWCB Material”, Proceeding of The International Conference on Advances in Production and Industrial Engineering, DOI :10.13140/RG.2.1.3550.4163, Pp 186-191, 2015.

[13] Tejas Patel, SaurinSheth, Bhavin S. Modi and Pathik Patel, "Experimental Investigation and comparison of regression model and artificial neural network to predict weld height in MIG welding for dual plate check valve:,Proceedings of International Conference on Advances in Materials and Product Design, DOI:10.13140/RG.2.1.3501.6002/1, Pp. 334-339, 2015.

[14] ShethSaurin, Bhavin S. Modi, P. M. George and Pratik Patel, "A Fuzzy Logic based Model to Predict MRR in Flashing Operation of Precision Steel Ball Manufacturing Process”, Procedia Materials Science, Volume 5, Pp. 1837-1845, 2014.

[15] ShethSaurin, Bhavin S. Modi, Tejas Patel and P. M. George, "A Fuzzy Logic Based Model to Predict Weld Width-A Case Study of Hard Facing Process Using MIG Welding on Dual Plate Check Valve”, Applied Mechanics and Materials, Volume 592, Pp. 8-12, 2014.

[16] ArindamMajumder, "Comparison of ANN with RSM in Predicting Surface Roughness with respect to Process Parameters in Nd: YAG Laser Drilling", International Journal of Engineering Science and Technology, Volume 2, Issue 10, Pp. 5175-5186, 2010.

[17] J. Krottmaier, "Optimizing Engineering Designs", Mc Graw- Hill Internatiaonal Editions, 1994.

[18] Robert F. Brewer, "Design of Experiments for Process Improvement and Quality Assurance”, Narosa Publishers, 1998.

[19] Aiwina Heng, Andy C.C. Tan, Joseph Mathewa, Neil Montgomery, Dragan Banjevic and Andrew K.S. Jardine, "Intelligent Condition-Based Prediction of Machinery Reliability”, Mechanical Systems and Signal Processing, Volume 23, Pp. 1600-1614, 2009 